\title{
Longitudinal study of externalizing behaviors in Latino/a adolescents: An examination of parenting and educational factors
}

\author{
Sergio B. Pereyra \\ Fresno State University \\ Roy A. Bean \\ Brigham Young University - Provo \\ Jeremy B. Yorgason \\ Brigham Young University - Provo \\ Chien-Ti Lee \\ Brigham Young University - Provo \\ Jonathan G. Sandberg

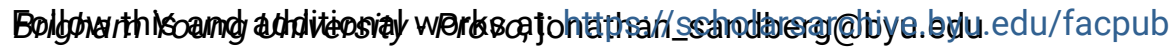 \\ Part of the Other Social and Behavioral Sciences Commons
}

See next page for additional authors

Original Publication Citation

Pereyra, S. B., Bean, R. A., Yorgason, J. B., Lee, C. T., Sandberg, J. G., \& Miller, R. B. (2019). Longitudinal study of externalizing behaviors in Latino/a adolescents: An examination of parenting and educational factors. Children and Youth Services Review, 107, 104513.

\section{BYU ScholarsArchive Citation}

Pereyra, Sergio B.; Bean, Roy A.; Yorgason, Jeremy B.; Lee, Chien-Ti; Sandberg, Jonathan G.; and Miller, Richard B., "Longitudinal study of externalizing behaviors in Latino/a adolescents: An examination of parenting and educational factors" (2019). Faculty Publications. 4188.

https://scholarsarchive.byu.edu/facpub/4188

This Peer-Reviewed Article is brought to you for free and open access by BYU ScholarsArchive. It has been accepted for inclusion in Faculty Publications by an authorized administrator of BYU ScholarsArchive. For more information, please contact ellen_amatangelo@byu.edu. 


\section{Authors}

Sergio B. Pereyra, Roy A. Bean, Jeremy B. Yorgason, Chien-Ti Lee, Jonathan G. Sandberg, and Richard B. Miller 


\title{
Longitudinal study of externalizing behaviors in Latino/a adolescents: An examination of parenting and educational factors
}

\author{
Sergio B. Pereyra, ${ }^{\mathrm{a}, *}$, Roy A. Bean ${ }^{\mathrm{b}}$, Jeremy B. Yorgason ${ }^{\mathrm{b}}$, Chien-Ti Lee ${ }^{\mathrm{b}}$, Jonathan G. Sandberg ${ }^{\mathrm{b}}$, \\ Richard B. Miller ${ }^{\mathrm{b}}$ \\ ${ }^{a}$ Department of Counselor Education and Rehabilitation in the Kremen School of Education at Fresno State University, Fresno, CA, United States \\ ${ }^{\mathrm{b}}$ School of Family Life at Brigham Young University, Provo, UT, United States
}

\section{A B S T R A C T}

As the Latino/a population increases externalizing behaviors among adolescents continue to concern researchers and clinicians. National Longitudinal Study of Adolescent Health (Add Health) data were used to analyze direct and indirect effects of parenting and academic factors on externalizing behavior among Latino/a adolescents over time, using latent growth curves and structural equation modeling (SEM). Results indicated that higher levels of maternal warmth, the adolescentteacher relationship, and academic achievement were all negatively associated with initial levels of externalizing behavior and in some cases negatively predicted the rate of change of externalizing behavior. Some predictors were also all found to be positively associated with academic achievement. Academic achievement acted as a mediator between most of the predictors and externalizing behavior. Implications are discussed.

\section{Introduction}

Externalizing behaviors can be defined as overt behaviors (e.g., aggression, delinquency, and substance use problems) that have a negative effect on an individual's external environment (Mason, Cauce, Gonzales, Hiraga, \& Grove, 1994). Although numerous studies have examined externalizing behaviors among adolescents (e.g., Mason et al., 1994; Perra, Fletcher, Bonell, Higgins, \& McCrystal, 2012, etc.), most studies have focused on the majority-culture population (referred to here as non-Latino/a Whites). In fact, even with increased attention to this topic for ethnic minorities, relatively few studies have focused on externalizing behaviors in Latino/a adolescents despite the group's status as the largest and one of the fastest growing ethnicities in the United States (Ennis, Ríos-Vargas, Albert, 2011). Latino/a youth in the U.S. are experiencing particularly challenging hardships as hate speech and intolerance continue to be promoted, particularly for those Latino/ as who come from immigrant families (Cardoso, Scott, Faulkner, \& Lane, 2018). For example, Parra-Cardona et al. (2019) recently point out that Latino/a youth from immigrant families are experiencing suicidal ideation based on bullying by classmates making fun of adolescents whose parents are undocumented. Another recent longitudinal study, demonstrated the deleterious effects of discrimination on Mexican-origin adolescents even when their parents were the ones specifically targeted (Park, Du, Wang, Williams, \& Alegria, 2018). Given the current socio-political climate of the U.S., the exploration of eco-systemic factors impacting externalizing behavior among a particularly vulnerable population (i.e., Latino/a youth) is imperative, while taking into account the macro-level context of Latino/a youth in the U.S.

In an effort to better understand the inter-relationships between key eco-systemic variables (Pantin, Schwartz, Sullivan, Prado, \& Szapocznik, 2004; Prado, Huang, Maldonado-Molina, Bandiera, Schwartz, de la Vega, Brown, \& Pantin, 2010), a comprehensive model of youth, familial, and educational variables was examined in relation to externalizing behavior. Academic achievement and its primary contributing factors such as student-teacher relationship quality are important but under-researched topics for this ethnic group, especially given the many disparities faced by Latino/a youth (Turcios-Cotto \& Milan, 2013). Not surprisingly, while connections have been made in the literature regarding academic achievement, the adolescent-teacher relationship and externalizing behaviors (e.g., Zimmermann, Schütte, Taskinen, \& Köller, 2013; Perra et al., 2012), very little is known about how these factors relate to each other among Latino/a adolescents. Ecodevelopmental theory, accounting for important eco-systemic social interactions and development over time (Pantin et al., 2004; Prado et al., 2010), provides the conceptual framework to analyze these particular variables and can help explain why they are significantly inter-related. An eco-developmental perspective can also be helpful when looking at predictors of externalizing behavior from adolescence into adulthood. While research shows that family dynamics are weak predictors of adulthood externalizing behavior among non-Latino/a Whites (Dubow, Boxer, \& Huesmann, 2008), longitudinal research among Latino/as shows that parenting (Amato \& Fowler, 2002) and

\footnotetext{
* Corresponding author.

E-mail address: spereyra@csufresno.edu (S.B. Pereyra).
} 
other environmental factors (Cano et al., 2015) can, in fact, influence externalizing behaviors.

As currently conceptualized, parental warmth and behavioral control are microsystemic parenting behaviors that, along with the adolescent-teacher relationship, help constitute the social interactions that cumulatively influence adolescent behavior (Prado et al., 2010). Since longitudinal research with ethnic minorities have demonstrated different influences of maternal and paternal parenting behaviors on adolescent externalizing behaviors (Shek, 2005; Shek \& Zhu, 2019), there is a need to test maternal and paternal influences on Latino/a adolescent outcomes separately. Academic achievement is conceptualized as a mechanism through which those parenting behaviors and the adolescent-teacher relationship impact Latino/a adolescent externalizing behavior over time. From an eco-developmental perspective (Pantin et al., 2004; Prado et al., 2010), Latino/a cultural values from the adolescent's macro-system provide a theoretical rationale for the inclusion of academic achievement as a mediator (Turcios-Cotto \& Milan, 2013; Barker, Cook, \& Borrego, 2010). The current study was also designed to move beyond past cross-sectional analyses, utilizing three waves of data from the ADD Health dataset to examine the impact of parenting behaviors and the adolescent-teacher relationship on Latino/a adolescent externalizing behavior through academic achievement.

\section{Literature review}

\subsection{Theoretical framework}

The foundation for this study is eco-developmental theory (Prado et al., 2010; Pantin et al., 2004), an integration of Bronfenbrenner's ecological systems theory (1979) and classical developmental theory (e.g., Braveman \& Barclay, 2009). Accordingly, adolescent functioning is theorized to be influenced by three interacting elements: the child's ecosystem, child development over time, and an emphasis on social interactions. As the first of these elements, eco-systemic factors are organized according to their proximity to the adolescent (following Bronfenbrenner's theory (1979)), including the family/parental system in which the adolescent is directly involved (microsystem), and interactions between other systems (e.g., school) and the family (mesosystem). As such, externalizing problems among Latino/a adolescents are conceptualized here as being influenced by parenting and schoolrelated factors from proximal microsystems and mesosystem interactions.

The Latino/a cultural value of "educación" or "ser bien educado" literally means to "be well educated", however, this term also includes connotations of being well mannered, respectful, and having high morals (Halgunseth, Ispa, \& Rudy, 2006; Turcios-Cotto \& Milan, 2013; Barker et al., 2010). Latino/a children "who perceive their parents as investing time in gaining knowledge about their lives and activities (or monitoring/ behavioral control) may perceive such efforts as evidence of fathers and mothers protecting them from exposure to external factors that detract from academic endeavors" (Henry, Merten, Plunkett, \& Sands, 2008, p. 581), while Latino/a children who perceive their parents to be more warm feel more encouraged to do well in school (Peterson, 2005). With the cultural value of "educación", these same children honor their parents endeavors and wishes for them to succeed in school (Turcios-Cotto \& Milan, 2013) as a mechanism to also avoid externalizing behavior. Research also shows that parental warmth can positively impact academic achievement (Boyce Rodgers \& Rose, 2001) and that parental monitoring is positively associated with Latino/a adolescent academic achievement (Henry et al., 2008). Since academic achievement has also been found to impact externalizing behavior in adolescents (Zimmermann et al., 2013; Diego, Field, \& Sanders, 2003), academic achievement has been proposed as a mechanistic pathway by which parenting factors (warmth and behavioral control) lead to externalizing behaviors among Latino/a adolescents.
As the second element, eco-developmental theory also recognizes the developmental nature of adolescent behavior (Prado et al., 2010), supporting a longitudinal examination of externalizing behavior. The third element, the social-interactional component of eco-developmental theory, pertains to relationship patterns and direct interactions between individuals and processes within and across levels of context, such as the family or school system (Pantin et al., 2004). The social context selected for examination in this study includes the adolescent's familial and school environment because most of the adolescent's time is spent in these two areas (Hyndman, Benson, \& Telford, 2016).

\subsection{Parenting and externalizing problems}

Baumrind (1978) theoretical work has guided numerous studies on parenting (e.g., Bulcroft, Carmody, \& Bulcroft, 1996), highlighting parental warmth and behavioral control as key parenting dimensions for Latino/a and non-Latino/a families (Mogro-Wilson, 2008). As in most studies, parental warmth is defined here as the amount of love, acceptance, and closeness that a child feels from their parents (White \& Renk, 2012). The literature is remarkably consistent in that parental warmth is generally predictive of lower rates of externalizing problem behaviors (e.g., White \& Renk, 2012). While developmental research has shown that problem behaviors in adolescence usually predicts externalizing behavior into adulthood (Dubow et al., 2008), longitudinal research also indicates that decreases in parental warmth predict increased levels of externalizing behaviors in adolescents (Wang, Kim, Anderson, Chen, \& Yan, 2012). Although studies linking parental warmth to externalizing behavior are less common among ethnically diverse populations, similar effects of parental warmth on externalizing behaviors have been shown in Latino/a families (e.g. Amato \& Fowler, 2002). In another study specific to Latino/as, Mogro-Wilson (2008) found that parental warmth directly and indirectly decreased alcohol use (a type of externalized problem).

The other key parenting dimension, behavioral control (Baumrind, 1978), refers to parental efforts to set limits, and is distinguished from psychological control in that it, "concerns active monitoring and regulation of the adolescent's activities and associations" (Kerr, Stattin, \& Özdemir, 2012, p.1541). Latino/a parents have often been characterized as being more strict, dominant, and more insistent on discipline (including more physical punishment) than non-Latino/a White parents (Florsheim, Tolan, \& Gorman-Smith, 1996); however, more recent research shows that Latino/a parents are more reluctant to use the physical discipline strategies commonly accepted in their countries-oforigin and that they are interested in learning more effective ways of behavioral control (Parra-Cardona et al., 2009). One interesting crosscultural study found that Latino/a parents were less restrictive in terms of children's intra-familial behaviors (e.g., amount of TV watched) but Latino/a parents used more extra-familial control (e.g., stricter curfews) than Anglo parents (Bulcroft et al., 1996).

\subsection{Gender-based differences in parenting}

There is a relatively small body of literature distinguishing the effects of maternal versus paternal parenting practices on Latino/a adolescent functioning. For example, Updegraff et al. (2009) found that mothers had more knowledge about their children's day-to-day activities than did the fathers in their study, and Crockett, Brown, Russell, and Shen (2007) found that adolescents reported more open communication with their mothers than fathers. Research with Latino/a families consistently suggests traditional parenting roles, with mothers as the primary caregivers and fathers as economic providers and authority figures (Cauce and Domenech-Rodríguez, 2002; Fuligni, 1998), with this division-of-labor even more pronounced among immigrant parents or those with strong cultural ties to Mexican heritage (Parra-Cardona, Cordova, Holtrop, Villaruel, \& Wieling, 2008; Raffaelli \& Ontai, 2001). With regards to the two parenting variables highlighted in the current 
study, traditional gender roles in parenting among Latino/a families suggest that Latina mothers are more inclined to provide parental warmth, while Latino fathers are more inclined to provide the discipline and behavioral control (Falicov, 1998). This study was designed explore differences between maternal and paternal parenting effects on externalizing behaviors while examining other systems in the adolescent's environment, such as the school system.

\subsection{Adolescent-teacher relationship}

When compared with other academic-related factors, such as a sense of school belonging, the student-teacher relationship has more predictive power as it pertains to youth outcomes (McNeely, 2005). Racial and ethnic minorities have been shown to experience less positive relationships with their teachers (Saft \& Pianta, 2001), which can be of particular concern given that student-teacher relationships have been found to influence academic outcomes (Košir \& Tement, 2014). For example, Baker (2006) found that students who had more conflictual relationships were at greater risk for poor academic achievement. Another study found that better student-teacher relationships were associated with improved academic outcomes among at-risk ethnic minority students (Decker, Dona, \& Christenson, 2007).

In studies of adolescent functioning, there is a growing acknowledgement of teachers' influence on student behavior (e.g., Jennings \& Greenberg, 2009). Recently, Diaz et al. (2017) found that more conflictual student-teacher relationships were associated with more externalizing behavior (defiance, aggression, conduct problems). The very limited number of longitudinal studies (e.g., Hamre \& Pianta, 2001) analyzing the association between student-teacher relationships and behavioral outcomes have utilized younger samples (children), meaning that even less is known about these relationships for adolescent populations across time. One longitudinal study that did target adolescents found that a positive adolescent-teacher relationship was linked to a reduction in externalizing behaviors for both males and females (Perra et al., 2012), yet research is still needed to examine these associations among Latino/a adolescents, who are often at higher risk of externalizing behaviors (Pereyra \& Bean, 2017).

\subsection{Academic achievement}

In using an eco-developmental perspective to examine Latino/a adolescent functioning, it is important to include academic factors given the amount of time that teens spend in a school environment and the Latino/a cultural value of "educación". More specifically, Latino/a parenting practices are organized around raising children to be "bien educado," which again, refers to an emphasis on children being wellbehaved, respectful to adults (includes teachers), educated and knowledgeable about their place in the larger community and world (Halgunseth et al., 2006; Turcios-Cotto \& Milan, 2013; Barker et al., 2010). While no studies were found linking behavioral control (as conceptualized here) with academic achievement, other findings suggest that lower levels of parental monitoring can be predictive of lower academic achievement (Boyce Rodgers \& Rose, 2001) and that lower levels of parental warmth can be detrimental to Latino/a adolescent academic achievement (Eamon \& Mulder, 2005).

There are, however, numerous studies that found a connection between academic achievement and externalizing behaviors (e.g., Zimmermann et al., 2013), indicating that students with higher academic achievement may be less at risk to engage in externalizing behavior (Diego et al., 2003). Not surprisingly, however, very little research has examined these factors in a Latino/a adolescent sample. Out of the small body of literature available, a few studies were found that show that academic achievement (as measured by GPA) can affect externalizing behavior among Latino/a youth (Vaughn, Kratz, \& D'Argent, 2011). In terms of longitudinal studies (and consistent with an ecodevelopmental perspective), school-related factors have also been shown to be robustly related to problem behaviors across three developmental stages (middle adolescence, late adolescence, and early adulthood) among ethnic minorities (Henry, Knight, \& Thornberry, 2012). Lastly, since parenting behaviors (Eamon \& Mulder, 2005) and the adolescent-teacher relationship (Decker et al., 2007) have been linked with academic achievement and academic achievement has separately been linked with externalizing behaviors (Diego et al., 2003), this study will simultaneously study the mediating role of academic achievement between parenting behaviors and the adolescent-teacher relationship and externalizing behaviors.

\subsection{The current study}

This study was designed to contribute to a limited-but-growing body of research literature focused Latino/a adolescents and families using an eco-developmental conceptualization (Pantin et al., 2004; Prado et al., 2010) to study several eco-systemic relationships across time. The purpose of this longitudinal study was to examine the predicting effects of parenting variables and the adolescent-teacher relationship on externalizing behavior over time through academic achievement (mediator), while controlling for adolescent gender and acculturation. The hypothesized model was examined across three waves of data and tested for the following hypotheses:

H1: We hypothesized that higher levels of parental warmth (both maternal and paternal), behavioral control, the adolescent-teacher relationship, and academic achievement would predict lower levels of externalizing behaviors (both initial levels and rate of change).

H2: We hypothesized that higher levels of parental warmth (both maternal and paternal), behavioral control and the adolescent-teacher relationship would predict higher levels of academic achievement.

H3: We hypothesized that all four predictor variables (maternal warmth, paternal warmth, behavioral control and the adolescentteacher relationship) would predict both initial levels (intercept) and the rate of change (slope) of externalizing behaviors through academic achievement (as a mediator).

\section{Method}

\subsection{Participants}

This study utilized a sample of 743 Latino/a adolescents drawn from Add Health data (see Harris, 2005 for details on the sampling design and data collection methodology). The Add Health study is a nationallyrepresentative, survey of adolescents in grades 7-12 conducted between 1994 and 2009. The sample for the current study was taken from the non-restrictive public dataset, comprised of 6504 respondents. Participants were limited to those who exclusively classified their ethnicity into Hispanic or Latino/a groups. In terms of country of origin, $48 \%$ reported being Mexican or Mexican-American, 4\% Chicano/Chicana, $18 \%$ Puerto Rican, $12 \%$ Central or South American, 18\% reported "Other Hispanic." Out of the 743 participants at Wave I, 358 (48.2\%) were male and 385 (51.8\%) were female. Additionally, 454 (61.1\%) participants reported being born in the U.S., 196 (26.4\%) reported being born outside the U.S., and 93 (12.5\%) did not to specify. In terms of language preference, $423(56.9 \%)$ participants reported speaking English in the home and $308(41.5 \%)$ spoke Spanish. Based on the demographics reported, it is suggested that this is a moderately acculturated group of Latino/a adolescents.

\subsection{Measures}

\subsubsection{Parental warmth}

The measure of parental warmth is comprised of four items, regarding the adolescent's report of parenting behaviors from Wave I 
(Mogro-Wilson, 2008; maternal warmth, Cronbach's alpha $=0.86$ and paternal warmth, Cronbach's alpha $=0.90$ ). For the first item, adolescents rated the emotional closeness of their relationship with each parent on a 5-point scale ranging from "not at all" (1) to "very much" (5). The other three items asked about the youth's perception of their parent being warm and loving to them, their satisfaction with the way they communicate with their parent, and their overall satisfaction with their relationship with their parent. All three of these items were recoded into a 5-point scale from "strongly disagree" (1) to "strongly agree" (5). A confirmatory factor analysis (CFA) was used to identify the items that loaded appropriately onto each scale and factor loadings for the maternal variable ranged from 0.59 to 0.97 and factor loadings for the paternal variable ranged from 0.82 to 0.95 .

\subsubsection{Parental behavioral control}

This adolescent-report measure focused on parental control of adolescent behaviors at Wave I (Mogro-Wilson, 2008). Adolescents responded to seven questions about whether they were allowed to make their own decisions on amount of television watched, on weekend curfew, dressing style, TV programs watched, bedtime on week nights, eating habits, and the people whom they hang around with. These dichotomous items were combined to create a latent variable of behavioral control and all of the items were labeled as "categorical" in Mplus software in order to be analyzed appropriately. Given their structure as dichotomous variables, a Kuder-Richardson 20 (KR20) internal consistency test was used to confirm reliability (KR20 $=0.66)$. A confirmatory factor analysis (CFA) was used to identify the items that loaded appropriately onto the scale and factor loadings ranged from 0.60 to 0.87 .

\subsubsection{Academic achievement}

Adolescent academic achievement was measured at Wave I using youth self-reports of recent grades in math, science, language arts, and social studies (Ryabov \& Van Hook, 2007; Cronbach's alpha $=0.69$ ). These four items were reported on a four-point scale and were recoded to reflect $4=$ "A", $3=$ "B", $2=$ "C", and $1=$ "D or lower". A confirmatory factor analysis (CFA) was used to identify the items that loaded appropriately onto each scale and factor loadings ranged from 0.58 to 0.73 .

\subsubsection{Adolescent-teacher relationship}

This measure consisted of three items describing the adolescent's perception of their relationship with teachers at Wave I. The three items that make up this latent variable include: how they feel their teachers care about them, whether they have trouble getting along with their teachers, and if they think that their teachers treat students fairly. All three items were rated by the adolescents on a 5-point scale ranging from "strongly agree" (1) to "strongly disagree" (5). A confirmatory factor analysis (CFA) was used to identify the items that loaded appropriately onto each scale; factor loadings were as follows: $0.58,0.65$, and 0.69. This measure has been utilized in previous Add Health-based studies (e.g., McNeely and Falci, 2004; Russell, Seif, \& Truong, 2001) despite the lower reliability coefficient (Cronbach's alpha $=0.49$ ).

\subsubsection{Externalizing behaviors}

Adolescent externalizing behaviors were measured using four selfreport items, based on the response categories of: "never," "1 or 2 times", " 3 or 4 times," and " 5 or more times". Only the four items that were measured consistently across all waves were included in this analysis. Items were assessed over the past 12 months and included: how often they damaged, how often they sold drugs, how often they stole (less than $\$ 50$ ), and how often they participated in a physical fight. Cronbach's alpha coefficients ranged from 0.68 to 0.84 across the three waves. A confirmatory factor analysis (CFA) was used to identify the items that loaded appropriately onto each scale and all factor loadings for the first wave ranged from 0.42 to 0.54 , from 0.45 to 0.68 for the second wave and from 0.43 to 0.66 , for the third wave.

\subsection{Analysis}

Structural equation modeling was used to test the hypothesized model. Direct and indirect effects were analyzed between the predictors (maternal/paternal warmth, behavioral control, adolescent-teacher relationship) and the outcome variable of adolescent externalizing behavior, via adolescent academic achievement. For the longitudinal portion of the analysis, an unconditional latent growth curve (LGC) model was first used to describe initial levels (intercept) and the rate of change (slope) of adolescent externalizing behavior with all four time points. Afterwards, predictor variables and adolescent academic achievement were then added to a conditional LGC model to test direct and indirect effects as hypothesized. It should be noted that assumptions of structural equation modeling and latent growth curve modeling and were met in this study (see Kline, 2010 for a detailed description of those assumptions).

For indirect effects, the bootstrap approach was selected because: (a) it does not rely on the restrictive assumption that the sampling distribution is normally distributed (Anderson, Durtschi, Solosky, \& Johnson, 2014), which is relevant because the externalizing behaviors variable (at each time point) was quite heavily skewed towards zero; and (b) it is considered to be the most appropriate way to examine indirect effects (Hayes, 2013; Hayes, Preacher, \& Myers, 2011). For this study, 5000 bootstrap samples were drawn to examine the indirect effects of all predictor variables (maternal/paternal warmth, behavioral control, and the adolescent-teacher relationship) and initial values and change in externalizing behavior, through academic achievement. The bootstrap method adjusts standard errors of the indirect effects so they are not artificially low (Kline, 2010).

Due to the complexity of the model, there were a few adjustments that needed to be made to the initial proposed analysis in order to achieve optimal results. In this instance, the latent scoring method was implemented due to the size of the current sample and longitudinal growth component. Since factor scores obtained from a confirmatory factor analysis (CFA) are equivalent to latent scores from a latent scoring perspective (Yang, Nay, \& Hoyle, 2010), the factor scores of the CFA performed on each variable employed in the model were used in place of the latent variables in the current analysis to estimate the final path model which was analyzed to test both direct and indirect effects on the growth curve.

\section{Results}

Descriptive statistics are reported for all variables (see Table 1) and bivariate correlations are presented in Table 2, with all significant correlations found to be in the expected direction. Model fit statistics for the unconditional LGC model revealed a Chi- Square coefficient of 100.808, $p<.001, \quad(d f=6)$, with the following fit indices: $\mathrm{CFI}=0.994$, TLI $=0.989$, RMSEA $=0.015$, and SRMR $=0.018$. Based on fit index standards, these results indicated that the model was a very good fit for the data based on the following recommendations: CFI values above 0.90 , RMSEA value below 0.05 , SRMR value below 0.08 (Hu \& Bentler, 1999). Means of the intercept $(\mu=0.59, p<.001)$ and of the slope $(\mu=-0.99, p<.01)$ were both significant, indicating that the baseline level of externalizing behavior was appreciably different from zero and that externalizing behaviors among this sample significantly declined over time. Although no significant variance was found in the slope, there was significant variance around the intercept $(\beta=0.17, p<0.001)$, suggesting that initial values of externalizing behavior varied across the sample. In terms of the control variables, adolescent gender was found to significantly impact the intercept $(p<0.001)$ and the slope $(p<0.001)$ of externalizing behavior, specifically that boys were more likely to engage in initial levels of externalizing behavior and of externalizing behavior over time. 
Table 1

Means, SDs, and Ranges for observed variables.

\begin{tabular}{|c|c|c|c|c|c|c|c|c|c|c|}
\hline & \multicolumn{4}{|c|}{ Adolescent females } & \multicolumn{4}{|c|}{ Adolescent males } & \multicolumn{2}{|l|}{$\mathrm{T}$ test } \\
\hline & Min-max & Range & Mean & SD & Min-max & Range & Mean & SD & $\mathrm{T}$ score & $P$ value \\
\hline Maternal warmth & $5-20$ & 15 & 16.56 & 3.40 & $5-20$ & 15 & 17.64 & 2.69 & 4.66 & 0.000 \\
\hline Paternal warmth & $5-20$ & 15 & 15.63 & 3.80 & $5-20$ & 15 & 16.35 & 3.50 & 2.19 & 0.029 \\
\hline Behavioral control & $0-5$ & 5 & 1.25 & 1.32 & $0-5$ & 5 & 1.26 & 1.38 & 0.16 & 0.872 \\
\hline Adol.-teacher relationship & $1-12$ & 11 & 8.55 & 2.02 & $1-12$ & 11 & 8.46 & 2.08 & -0.56 & 0.583 \\
\hline Academic achievement & $4-16$ & 12 & 10.89 & 2.89 & $4-16$ & 12 & 10.50 & 2.83 & -1.51 & 0.131 \\
\hline Externalizing behavior $\mathrm{T} 1$ & $0-4$ & 4 & 0.98 & 1.58 & $0-4$ & 4 & 1.37 & 2.06 & 2.84 & 0.005 \\
\hline Externalizing behavior T2 & $0-4$ & 4 & 0.89 & 1.75 & $0-4$ & 4 & 1.11 & 1.54 & 0.29 & 0.774 \\
\hline Externalizing behavior T3 & $0-4$ & 4 & 0.43 & 1.09 & $0-4$ & 4 & 1.03 & 1.02 & 0.06 & 0.949 \\
\hline
\end{tabular}

Acculturation was also found to significantly impact the intercept $(p<0.001)$ and the slope $(p<0.001)$ of externalizing behavior, specifically that more acculturated were more likely to engage in initial levels of externalizing behavior and of externalizing behavior over time.

\subsection{Conditional latent growth curve model}

\subsubsection{Direct effects}

Predictor variables were then added to estimate a conditional latent growth curve model in order to test associations between predictors and initial levels and growth in externalizing behavior. The model fit for the conditional (final) LGC model was adequate $\left(\chi^{2}=478.716\right.$, $p<0.001, \quad d f=45, \quad n=595, \quad$ CFI $=0.946, \quad$ TLI $=0.889$, RMSEA $=0.042$, and SRMR $=0.030$ ). The full model presentation can be found in Fig. 1. Several key hypothesized relationships are emphasized here. Regarding the first hypothesis (i.e., that independent variables will be negatively associated with the intercept and slope of externalizing behavior), maternal warmth was negatively associated with initial levels of externalizing behavior $(\beta=-0.16, p<.05)$ and the adolescent-teacher relationship was negatively associated with initial levels of externalizing behavior $(\beta=-0.25, p<.01)$. Academic achievement also had a significantly negative relationship with initial levels of externalizing behavior $(\beta=-0.22, p<.01)$. In terms of the trajectories of externalizing behavior, the adolescent-teacher relationship was negatively predictive of the rate of change of externalizing behavior $(\beta=-0.29, p<.01)$. Academic achievement was also negatively predictive of the rate of change of externalizing behavior over time $(\beta=-0.28, p<.01)$.

In answer to the second hypothesis (i.e., that all four of the predictor variables will be positively associated with academic achievement), paternal warmth had a significantly positive relationship with academic achievement $(\beta=0.29, p<0.001)$ and behavioral control had a significantly positive relationship with academic achievement $(\beta=0.08$, $p<0.01)$. The adolescent- teacher relationship was also positively associated with academic achievement $(\beta=0.66, p<0.001)$ as expected.

\subsubsection{Indirect effects}

Although paternal warmth had a non-significant direct effect on initial levels of externalizing behavior (intercept), it was found to have a significant negative association with initial levels of externalizing behavior through academic achievement $(\beta=-0.06, p<.05,95 \%$ biased-corrected CI $[-0.03,-0.11])$. Similarly, behavioral control was found to have a significant negative association with initial levels of externalizing behavior through academic achievement $(\beta=-0.02$, $p<0.05,95 \%$ biased-corrected CI $[-0.01,-0.04]$ ). The adolescentteacher relationship was also found to have a significant negative association with initial levels of externalizing behavior through academic achievement $(\beta=-0.02, p<0.01,95 \%$ biased-corrected CI $[-0.24$, $-0.06])$.

In relation to the rate of change in externalizing behavior (slope), paternal warmth was negatively related to externalizing behavior through academic achievement $(\beta=-0.08, p<.05,95 \%$ biasedcorrected CI $[-0.15,-0.04])$, signifying that higher levels of paternal warmth predicted more rapid declines in the trajectory of externalizing behavior though academic achievement. Behavioral control was negatively predictive of externalizing behavior over time through academic achievement $(\beta=-0.02, p<.05,95 \%$ biased-corrected CI $[-0.05$, $-0.08]$ ). Finally, the adolescent-teacher relationship was negatively predictive of the slope of externalizing behavior through academic achievement $(\beta=-0.18, p<.01,95 \%$ biased-corrected CI $[-0.08$, $-0.32])$. All other paths were non-significant. The overall variance $\left(R^{2}\right)$ explained in the model was $29 \%$ for the initial levels of externalizing behavior and $36 \%$ for the rate of change of externalizing behavior.

In terms of maternal and paternal comparisons of parental warmth, both turned out to have vastly different effects on the adolescent outcomes. Maternal warmth had the only direct effect on initial levels of externalizing behavior (negative association), while paternal warmth had the only direct effect on academic achievement (positive association). Paternal warmth had a significant indirect relationship with initial levels of externalizing behavior and with externalizing behavior over time through academic achievement, while maternal warmth had no such indirect effects.

Table 2

Bivariate correlations for study variables for latino girls and boys.

\begin{tabular}{|c|c|c|c|c|c|c|c|c|}
\hline & 1 & 2 & 3 & 4 & 5 & 6 & 7 & 8 \\
\hline 1. Maternal warmth & - & $0.544 * *$ & 0.009 & $0.193^{* *}$ & -0.083 & $-0.131 *$ & -0.035 & -0.061 \\
\hline 2. Paternal warmth & $0.496 * *$ & - & 0.029 & $0.210 * *$ & -0.163 & $-0.201 * *$ & -0.026 & -0.102 \\
\hline 3. Behavioral control & -0.059 & -0.002 & - & 0.057 & 0.040 & $-0.118^{*}$ & $0.149^{*}$ & -0.006 \\
\hline 4. Adol.-teacher relationship & $0.195^{* *}$ & $0.260 * *$ & 0.017 & - & 0.098 & $-0.380 * *$ & 0.031 & 0.018 \\
\hline 5. Academic achievement & 0.033 & 0.070 & -0.015 & $0.322^{* *}$ & - & $-0.237 * *$ & -0.112 & 0.065 \\
\hline 6. Externalizing behavior $\mathrm{T} 1$ & $-0.254 * *$ & $-0.192 * *$ & 0.031 & $-0.223 * *$ & $-0.254 * *$ & - & -0.014 & -0.051 \\
\hline 7. Externalizing behavior $\mathrm{T} 2$ & 0.039 & -0.039 & -0.033 & -0.027 & 0.030 & $0.151^{*}$ & - & -0.085 \\
\hline 8. Externalizing behavior $\mathrm{T} 3$ & -0.026 & -0.053 & 0.007 & -0.017 & 0.047 & 0.100 & -0.017 & - \\
\hline
\end{tabular}

Notes: ${ }^{*} p<.05 .{ }^{* *} p<.01$. Correlations below the diagonal correspond to girls, above the diagonal are for boys. 


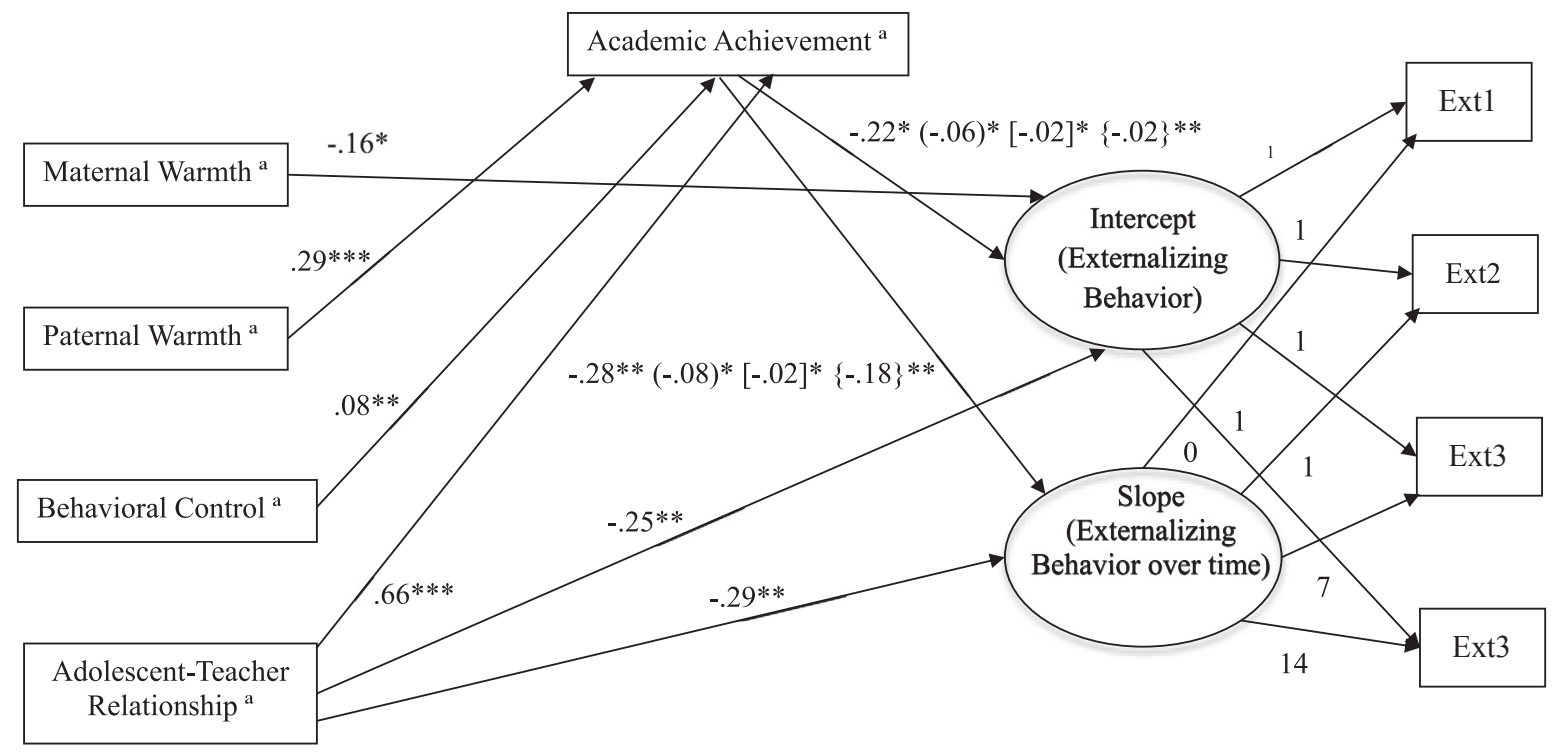

Fig. 1. Structural equation model of parenting and school factors in relation to externalized problem behaviors in latino youth. Model fit statistics: $\chi^{2}=478.716$, $p<.001, d f=45$, CFI $=0.946$, TLI $=0.889$, RMSEA $=0.042$, and SRMR $=0.030 * p<.05 . * * p<.01 .{ }^{* * *} p<.001$. Notes: significant direct paths, (indirect effects for paternal warmth in parentheses), [indirect effects for behavioral control in brackets], \{indirect effects for adolescent-teacher relationship in other brackets ${ }^{\text {a }}$ Factor score obtained through a confirmatory factor analysis (CFA) of a latent variable.

\section{Discussion}

\subsection{Predicting variables of externalizing behavior}

In regards to the first hypothesis, and consistent with the literature regarding gender differences among Latino/a parenting behaviors (Behnke et al., 2008), maternal warmth was significantly related to youth externalizing behaviors whereas paternal warmth was not associated significantly. These differential findings may be attributed to gender-differences in traditional Latino/a childrearing roles, where mothers are typically more responsible for childcare, which may translate to a corresponding greater influence in disrupting or preventing problem behaviors (Falicov, 1998). Moreover, research with non-Latino/a Whites frequently shows that maternal warmth is a stronger predictor than paternal warmth regarding externalizing behavior (White \& Renk, 2012). Research has also shown that mothers typically spend more time with their adolescent children than do fathers (Repinski \& Zook, 2005), which is also consist with portrayals of Latino/a family functioning (Falicov, 1998). While paternal warmth was not directly found to be significantly related to externalizing behavior in the current study, these results should be interpreted with caution so as not to undermine the importance of Latino fathers in the parenting of their children. Consequently, Parra-Cardona et al. (2017) also recently found that when paternal warmth was strengthened through a culturally sensitive parenting intervention program, the effects on adolescent externalizing behavior were notorious. Even though maternal warmth was the only parenting variable to have a direct impact on externalizing behavior in the current study, culturally sensitive parenting training programs are still highly encouraged, especially ones specifically addressing discrimination given the current anti-immigration climate in the U.S. (Parra-Cardona et al., 2017; Cardoso et al., 2018; Parra-Cardona et al., 2019).

The first hypothesis was also supported through the adolescentteacher relationship variable. For the current sample, a better adolescent-teacher relationship was not only associated with lower initial levels of externalizing behaviors, but it was also predictive of steeper declining slopes of externalizing behavior over time. This finding is consistent with previous longitudinal studies (e.g., Hamre \& Pianta, 2001) of the effects of the student-teacher relationship on externalizing behavior, and is also consistent with the eco-developmental perspective that postulates that social interactions can impact adolescent development over time (Prado et al., 2010).

Results from this study also supported the first hypothesis in that higher levels of academic achievement were negatively associated with lower initial levels of externalizing behaviors and were predictive of less externalizing behavior over time. This finding is consistent with previous studies demonstrating the link between academic achievement and externalizing behavior (Diego et al., 2003). Similar to Zimmermann et al. (2013), academic achievement was also predictive of less externalizing behavior over time. When examining the transition from adolescence into adulthood, this finding also coincides with research showing that school-related factors can be strong predictors of problem behaviors across all three developmental stages (Henry et al., 2012). Guided by the eco-developmental perspective, higher-achieving adolescents are less likely to exhibit externalizing behavior because of influential social interactions with parents (Boyce Rodgers \& Rose, 2001) and teachers (Decker et al., 2007) who model appropriate behaviors and/or hold them accountable for their actions.

\subsection{Predictive variables and academic achievement}

The second hypothesis was also partially supported in that all of the parenting predictor variables except for maternal warmth had a significant direct effect on Latino/a adolescents' academic achievement. Consistent with previous literature (Boyce Rodgers \& Rose, 2001; Taylor, Hinton, \& Wilson, 1995), paternal warmth was positively associated with academic achievement. Behavioral control was also positively associated with academic achievement and although it was difficult to find studies connecting behavioral control and academic achievement (especially among Latino/a families), the available literature does support the current finding as it relates to Latino/a parents' efforts to monitoring their children in terms of their academic achievement (Santiago, Gudiño, Baweja, \& Nadeem, 2014). From an eco-developmental perspective (Prado et al., 2010; Pantin et al., 2004), Latino/a parents can extend the impact of their parenting, whether through their warmth (paternal) or through behavioral control, to other parts of the child's ecosystem that go beyond the home, such as their academic achievement.

As hypothesized, and as supported by the literature (i.e., Košir \& Tement, 2014), the adolescent-teacher relationship was found to be 
positively associated with academic achievement. While research on these interactions is limited for Latino/a samples, the findings of this study coincides with Rassiger (2012), which found that a positive adolescent-teacher relationship was predictive of academic success among at-risk Latino/a youth. From an eco-developmental perspective, a close relationship and good adolescent-teacher interactions are an important component to academic success among Latino/a youth who have been found to desire deeper and more connected relationships with their teachers (Cammarota \& Romero, 2006).

\subsection{Indirect effects of academic achievement on externalizing behavior}

In regards to the final hypothesis, two very notable findings were identified in that academic achievement completely mediated the relationship between the parenting variables and adolescent externalizing behavior. First, paternal warmth only had an indirect effect on externalizing behavior at initial levels and over time through academic achievement. This finding is not in line with previous research that identifies parental warmth as a factor to directly impact externalizing behavior (Wang et al., 2012; Mogro-Wilson, 2008; Amato \& Fowler, 2002). From an eco-developmental perspective, academic achievement becomes the eco-systemic factor (from the macrosystem) through which a Latino father's warmth impacts his children's externalizing behavior because of the cultural value of "educación" (Halgunseth et al., 2006; Turcios-Cotto \& Milan, 2013; Barker et al., 2010). Specifically, the more warmth a Latino/a adolescent receives the more he or she will want to perform better in school which will not only reduce the risk of initial levels of externalizing behaviors but also in the long run.

Secondly, the third hypothesis received partial validation as academic achievement was found to completely mediate the relationship between behavioral control and externalizing behavior among Latino/a adolescents. While it was more difficult to tie these findings back to the literature given the scarcity of studies using similar conceptualizations of behavioral control and its direct impact on externalizing behavior, this finding also belies Mogro-Wlison's (2008) study in that behavioral control was only indirectly predictive of externalizing behavior through academic achievement. Although, this finding is consistent with studies showing deconstructed or separated paths of positive relationships between parental monitoring (a form of behavioral control) and more favorable academic outcomes, and negative relationships between higher academic achievement and externalizing behavior (Bryant \& Zimmermann, 2002; Diego et al., 2003; Hallfors, Cho, Brodish, Flewelling, \& Khatapoush, 2006). Similar to parental warmth, and using an eco-developemental framework (Prado et al., 2010; Pantin et al., 2004) along with the theoretical influence of "educación" (Halgunseth et al., 2006; Turcios-Cotto \& Milan, 2013; Barker et al., 2010), as Latino/a parents' efforts to regulate behavior, monitor and set limits increases, their adolescent children improve their academic performance which then deters them from engaging in externalizing behavior in the short term and long term.

Finally, the third hypothesis was partially supported in that the adolescent-teacher relationship had an indirect effect on externalizing behavior at initial levels and over time through academic achievement. These findings suggest that healthy relationships with teachers aid Latino/a youth (directly and indirectly) in both academic and behavioral ways. Previous research has separately indicated that the adolescent-teacher relationship can influence academic achievement (Decker et al., 2007) and that academic achievement can influence externalizing behavior (Perra et al., 2012), but this study shows that academic achievement can act as a mechanism between those factors in Latino/a adolescents. While no other studies were found analyzing the mediating effects of academic achievement on externalizing behavior, this study's findings are consistent with those few which find supporting evidence of academic achievement as a factor of indirect effects in Latino/a adolescent adjustment (e.g., Zychinski \& Polo, 2012).

\subsection{Implications for future research}

Important outcomes were found regarding youth, familial, and educational variables among Latino/a adolescents in this study. When considering Latino/a parenting from an eco-developmental perspective and specifically at the macro-systemic level, oppression and discrimination are salient factors that can be addressed to reduce the challenges faced by Latino/as youth in the U.S. currently. For example, Cardoso et al. (2018) recently describe the critical role that parenting plays as a shield against intense external stressors in immigrant families and Parra-Cardona et al. (2019) show that prevention initiatives greatly improve when oppression and discrimination are overtly addressed as opposed to when they are left out. Researchers are urged to incorporate additional macro-related variables, such as climates of exclusion, discrimination and oppression, which are directly related to the main variables guiding this research (parenting variables, academic achievement, youth outcomes), but were not directly measured or studied. Also, a positive adolescent-teacher relationship may not only be a precursor of academic achievement and protective factor for externalizing behavior, but also a critical protective factor against pervasive macro-related stressors experienced by vulnerable Latino/a youth in classrooms (Parra-Cardona et al., 2019) in this socio-political climate, which can be explicitly tested.

\section{Conclusion}

This study offers a valuable contribution to the Latino/a adolescent behavioral literature; however, its reliance on a secondary dataset (Add Health) did feature some accompanying disadvantages. These include: the low reliability coefficient for the adolescent-teacher relationship variable and the nature of parental behavioral control (maternal and paternal efforts not collected separately). A related limitation was the omission of parental and teacher perspectives, as adolescent self-reports were used for all of the measures employed in this study.

In support of previous research, the results indicated that maternal warmth, the adolescent-teacher relationship and academic achievement were all negatively associated with initial levels of externalizing behavior. The adolescent-teacher relationship and academic achievement were found to be negatively predictive of the rate of change of externalizing behavior. In addition, academic achievement was found to be a significant indirect factor for the negative relationship between paternal warmth and behavioral control and both the intercept and slope of externalizing behavior. Lastly, a direct and indirect effect was found between the adolescent-teacher relationship and both initial levels of externalizing behavior and externalizing behavior over time through academic achievement. With the increasingly intolerant sociopolitical climate of the U.S. (Cardoso et al., 2018; Parra-Cardona et al., 2019), Latino/a adolescents (especially those from immigrant families) continue to be a susceptible population at risk of increasing externalizing behavior (Pereyra \& Bean, 2017), however the current study demonstrates how parents and teachers can become vital to lowering those risks both in the short term and long term.

\section{Declaration of Competing Interest}

The authors declared that there is no conflict of interest.

\section{Appendix A. Supplementary material}

Supplementary data to this article can be found online at https:// doi.org/10.1016/j.childyouth.2019.104513.

\section{References}

Amato, P. R., \& Fowler, F. (2002). Parenting practices, child adjustment, and family diversity. Journal of Marriage and Family, 64(3), 703-716. 
Anderson, J., Durtschi, J., Solosky, K. L., \& Johnson, M. D. (2014). Mediation and moderation: Conceptual foundations and analytical applications. In L. Johnson, \& R. Miller (Eds.). Advanced methods in family therapy research: A focus on validity and change (pp. 254-279). New York, NY: Routledge.

Baker, J. A. (2006). Contributions of teacher-child relationships to positive adjustment during elementary school. Journal of School Psychology, 44, 211-229.

Barker, C. H., Cook, K. L., \& Borrego, J., Jr. (2010). Addressing cultural variables in parent training programs with Latino families. Cognitive and Behavioral Practice, 17, $157-166$.

Baumrind, D. (1978). Parental disciplinary patterns and social competence in children. Youth and Society, 9, 239-276.

Behnke, A. O., Macdermid, S. M., Coltrane, S. L., Parke, R. D., Duffy, S., \& Widaman, K. F. (2008). Family cohesion in the lives of Mexican American and European American parents. Journal of Marriage and Family, 70(4), 1045-1059.

Boyce Rodgers, K., \& Rose, H. A. (2001). Personal, family, and school factors related to adolescent academic achievement: A comparison by family structure. Marriage \& Family Review, 33(4), 47-61.

Braveman, P., \& Barclay, C. (2009). Health disparities beginning in childhood: A lifecourse perspective. Pediatrics, 124, 163-175.

Bronfenbrenner, U. (1979). Contexts of child rearing: Problems and prospects. American Psychologist, 34, 844-850.

Bryant, A. L., \& Zimmermann, M. A. (2002). Examining the effects of academic beliefs and behaviors on changes in substance use among urban adolescents. Journal of Educational Psychology, 94(3), 621-637.

Bulcroft, R. A., Carmody, D. C., \& Bulcroft, K. A. (1996). Patterns of parental independence giving to adolescents: Variations by race, age, and gender of child. Journal of Marriage and Family, 58, 866-883.

Cammarota, J., \& Romero, A. (2006). A critically compassionate pedagogy for Latino youth. Latino Studies, 4, 305-312.

Cano, M. A., et al. (2015). Depressive symptoms and externalizing behaviors among Hispanic immigrant adolescents: Examining longitudinal effects of cultural stress. Journal of Adolescence, 42, 31-39.

Cardoso, J. B., Scott, J. L., Faulkner, M., \& Lane, L. B. (2018). Parenting in the context of deportation. Journal of Marriage and the Family, 80, 301-316.

Cauce, A. M., \& Domenech-Rodríguez, M. (2002). Latino families: Myths and realities. In J. M. Contreras, K. A. Kerns, \& A. M. Neal-Barnett (Eds.). Latino children and families in the United States: Current research and future directions (pp. 3-25). Westport, CT: Praeger Publishers/Greenwood Publishing Group.

Crockett, L. J., Brown, J., Russell, S. T., \& Shen, Y. (2007). The meaning of good parentchild relationships for Mexican American adolescents. Journal of Research on Adolescence, 17, 639-668.

Decker, D. M., Dona, D. P., \& Christenson, S. L. (2007). Behaviorally at-risk African American students: The importance of student-teacher relationships for student outcomes. Journal of School Psychology, 45, 83-109.

Diaz, A., Eisenberg, N., Valiente, C., Vanschyndel, S., Spinrad, T., Berger, R., Hernandez, M., Silva, K., \& Southworth, J. (2017). Relations of positive and negative expressivity and effortful control to kindergarteners' student-teacher relationship, academic engagement, and externalizing problems at school. Journal of Research in Personality, 67, 3-14.

Diego, M. A., Field, T. M., \& Sanders, C. E. (2003). Academic performance, popularity, and depression predict adolescent substance use. Adolescence, 38, 35-42.

Dubow, E. F., Boxer, P., \& Huesmann, L. R. (2008). Childhood and adolescent predictors of early and middle adulthood alcohol use and problem drinking: The Columbia county longitudinal study. Addiction, 103(Suppl. 1), 36-47.

Eamon, M. K., \& Mulder, C. (2005). Predicting antisocial behavior among Latino young adolescents: An ecological systems analysis. American Journal of Orthopsychiatry, 75(1), 117-127.

Ennis, S. R., Ríos-Vargas, M., \& Albert, N. G. (2011). The Hispanic population: 2010. 2010 Census briefs (C2010BR-04). Washington, DC: Government Printing Office.

Falicov, C. J. (1998). Latino families in therapy: A guide to multicultural practice. New York, NY: Guilford Press.

Florsheim, P., Tolan, P. H., \& Gorman-Smith, D. (1996). Family processes and risk for externalizing behavior problems among African American and Hispanic boys. Journal of Consulting and Clinical Psychology, 64, 1222-1230.

Fuligni, A. J. (1998). Authority, autonomy, and parent-adolescent conflict and cohesion: A study of adolescents from Mexican, Chinese, Filipino, and European backgrounds. Developmental Psychology, 34(4), 782-792.

Halgunseth, L., Ispa, J., \& Rudy, D. (2006). Parental Control in latino families: An integrated review of the literature. Child Development, 77(5), 1282-1297.

Hallfors, D., Cho, H., Brodish, P. H., Flewelling, R., \& Khatapoush, S. (2006). Identifying high school students "at risk" for substance use and other behavioral problems: Implications for prevention. Substance Use and Misuse, 41, 1-15.

Hamre, B. K., \& Pianta, R. C. (2001). Early teacher-child relationships and the trajectory of children's school outcomes through eighth grade. Child Development, 72, 625-638.

Harris, K. M. (2005). Design features of add health. Unpublished manuscriptChapel Hill, North Careolina, Carolina: Population Center, University of North Carolina.

Hayes, A. F., Preacher, K. J., \& Myers, T. A. (2011). Mediation and the estimation of indirect effects in political communication research. In E. P. Bucy, \& R. Lance Holbert (Eds.). Sourcebook for political communication research: Methods, measures, and analytical techniques (pp. 434-465). New York: Routledge.

Hayes, A. F. (2013). Introduction to mediation, moderation, and conditional process analysis: A regression-based approach. New York: Guilford.

Henry, C. S., Merten, M. J., Plunkett, S. W., \& Sands, T. (2008). Neighborhood, parenting, and adolescent factors and academic achievement in Latino adolescents from immigrant families. Family Relations, 57(5), 579-590.

Henry, K. L., Knight, K. E., \& Thornberry, T. P. (2012). School disengagement as a predictor of dropout, delinquency, and problem substance use during adolescence and early adulthood. Journal of Youth and Adolescence, 41(2), 156-166.

Hu, L. T., \& Bentler, P. M. (1999). Cutoff criteria for fit indexes in covariance structure analysis: conventional criteria versus new alternatives. Structural Equation Modeling, 6(1), 1-55.

Hyndman, B., Benson, A., \& Telford, A. (2016). Exploring the influences on children's school playground activities. American Journal of Play, 8(3), 325-344.

Jennings, P. A., \& Greenberg, M. T. (2009). The prosocial classroom: Teacher social and emotional competence in relation to student and classroom outcomes. Review of Educational Research, 79, 491-525.

Kerr, M., Stattin, H., \& Özdemir, M. (2012). Perceived parenting style and adolescent adjustment: Revisiting directions of effects and the role of parental knowledge. Developmental Psychology, 48(6), 1540-1553.

Kline, R. B. (2010). Principles and practice of structural equation modeling (3rd). New York: Guilford Press.

Košir, K., \& Tement, S. (2014). Teacher-student relationship and academic achievement: A cross- lagged longitudinal study on three different age groups. European Journal of Psychology of Education, 29(3), 409-428.

Mason, C. A., Cauce, A. M., Gonzales, N., Hiraga, Y., \& Grove, K. (1994). An ecological model of externalizing behaviors in African-American adolescents: No family is an island. Journal of Research on Adolescence, Special issue: Affective Processes in Adolescence, 4(4), 639-655.

McNeely, C. A., \& Falci, C. (2004). School connectedness and the transition into and out of health-risk behavior among adolescents: A comparison of social belonging and teacher support. Journal of School Health, 74, 284-292.

McNeely, C. A. (2005). Connection to school. In K. A. Moore, \& L. H. Lippman (Eds.). What do children need to flourish?: Conceptualizing and measuring indicators of positive development (pp. 289-303). New York, NY: Springer.

Mogro-Wilson, C. (2008). The influence of parental warmth and control on Latino adolescent alcohol use. Hispanic Journal of Behavioral Sciences, 30(1), 89-105.

Pantin, H., Schwartz, S. J., Sullivan, S., Prado, G., \& Szapocznik, J. (2004). Ecodevelopmental HIV prevention programs for Hispanic adolescents. American Journal of Orthopsychiatry, 74, 545-558.

Park, I. J. K., Du, H., Wang, L., Williams, D. R., \& Alegria, M. (2018). Racial/ethnic discrimination and mental health in Mexican-origin youths and their parents: Testing the "linked lives" hypothesis. Journal of Adolescent Health, 62, 480-487.

Parra-Cardona, J. R., Bybee, D., Sullivan, C. M., Domenech Rodrıguez, M. M., Dates, B., Tams, L., et al. (2017). Examining the impact of differential cultural adaptation with Latina/o immigrants exposed to adapted parent training interventions. Journal of Consulting and Clinical Psychology, 85, 58-71.

Parra-Cardona, J. R., Cordova, D., Holtrop, K., Villaruel, F. A., \& Wieling, E. (2008). Shared ancestry, evolving stories: Similar and contrasting life experiences described by foreign born and U. S. born Latino parents. Family Process, 47(2), 157-172.

Parra-Cardona, J. R., Holtrop, K., Cordova, D., Escobar-Chew, A. R., Horsford, S., Tams, L., Villaruel, F. A., Villalobos, G., Dates, B., Anthony, J. C., \& Fitzgerald, H. E. (2009). "Queremos aprender": Latino immigrants' call to integrate cultural adaptation with best practice knowledge in a parenting intervention. Family Process, 48(2), 211-231.

Parra-Cardona, J. R., López-Zerón, G., Leija, S. G., Maas, M. K., Villa, M., Zamudio, E., Arredondo, M., Yeh, H. H., \& Domenech Rodríguez, M. M. (2019). A culturally adapted intervention for Mexican-origin parents of adolescents: The need to overtly address culture and discrimination in evidence-based practice. Family Process, 58, 334-352.

Peterson, G. W. (2005). Family influences on adolescent development. In T. P. Gullotta, \& G. R. Adams (Eds.). Handbook of adolescent behavioral problems: Evidence-based approaches to prevention and treatment (pp. 27-55). New York: Springer.

Pereyra, S. B., \& Bean, R. A. (2017). Latino adolescent substance use: A mediating model of inter-parental conflict, deviant peer associations, and parenting. Children and Youth Services Review, 76, 154-162.

Perra, O., Fletcher, A., Bonell, C., Higgins, K., \& McCrystal, P. (2012). School-related predictors of smoking, drinking and drug use: Evidence from the belfast youth development study. Journal of Adolescence, 35(2), 315-324.

Prado, G., Huang, S., Maldonado-Molina, M., Bandiera, F., Schwartz, S. J., de la Vega, P., Brown, C. H., \& Pantin, H. (2010). An empirical test of ecodevelopmental theory in predicting HIV risk behaviors among Hispanic youth. Health Education and Behavior, 37(1), 97-114.

Raffaelli, M., \& Ontai, L. L. (2001). Gender socialization in Latino/a families: Results from two retrospective studies. Sex Roles, 50, 287-299.

Rassiger, C. A. (2012). Student-teacher relationships and academic success in at-risk latino and black middle school students. Dissertation Abstracts International Section A: Humanities and Social Sciences, 72(7-A), 2577-2702.

Repinski, D. J., \& Zook, J. M. (2005). Three measures of closeness in adolescents' relationships with parents and friends: Variations and developmental significance. Personal Relationships, 12, 79-102.

Russell, S. T., Seif, H., \& Truong, N. (2001). School outcomes of sexual minority youth in the United States: Evidence from a national study. Journal of Adolescence, 24(1), 111-127.

Ryabov, I. K., \& Van Hook, J. (2007). School segregation and academic achievement among hispanic children. Social Science Research, 36(2), 767-788.

Saft, E. W., \& Pianta, R. C. (2001). Teachers' perceptions of their relationships with students: Effects of child age, gender, and ethnicity of teachers and children. School Psychology Quarterly, 16(2), 125-141.

Santiago, C. D., Gudiño, O. G., Baweja, S., \& Nadeem, E. (2014). Academic achievement among immigrant and U.S.-born Latino adolescents: Associations with cultural, family, and acculturation factors. Journal of Community Psychology, 42(6), 735-747.

Shek, D. T. L. (2005). Paternal and maternal influences on the psychological well-being, substance abuse, and delinquency of Chinese adolescents experiencing economic 
disadvantage. Journal of Clinical Psychology, 61(3), 219-234.

Shek, D. T. L., \& Zhu, X. Q. (2019). Paternal and maternal influence on delinquency among early adolescents in Hong Kong. International Journal of Environmental Research and Public Health, 16(8), 1338-1362.

Taylor, L. C., Hinton, I. D., \& Wilson, M. N. (1995). Parental influences on academic achievement in African-American students. Journal of Child and Family Studies, 4(3), 293-302.

Turcios-Cotto, V. Y., \& Milan, S. (2013). Racial/ethnic differences in the educational expectations of adolescents: Does pursuing higher education mean something different to Latino students compared to white and black students? Journal of Youth and Adolescence, 42(9), 1399-1412.

Updegraff, K. A., Delgado, M. Y., \& Wheeler, L. A. (2009). Exploring mothers' and fathers' relationships with sons versus daughters: Links to adolescent adjustment in Mexican immigrant families. Sex Roles, 60(7-8), 559-574.

Vaughn, E. L., Kratz, L., \& D’Argent, J. (2011). Academics and substance use among Latino adolescents: Results from a national study. Journal of Ethnicity in Substance
Abuse, 10, 147-161.

Wang, Y., Kim, S., Anderson, E., Chen, A., \& Yan, N. (2012). Parent-child acculturation discrepancy, perceived parental knowledge, peer deviance, and adolescent delinquency in Chinese immigrant families. Journal of Youth and Adolescence, 41(7), 907-919.

White, R., \& Renk, K. (2012). Externalizing behavior problems during adolescence: An ecological perspective. Journal of Child and Family Studies, 21(1), 158-171.

Yang, C., Nay, S., \& Hoyle, R. H. (2010). Three approaches to using lengthy ordinal scales in structural equation models: Parceling, latent scoring, and shortening scales. Applied Psychological Measurement, 34(2), 122-142.

Zimmermann, F., Schütte, K., Taskinen, P., \& Köller, O. (2013). Reciprocal effects between adolescent externalizing problems and measures of achievement. Journal of Educational Psychology, 105(3), 747-761.

Zychinski, K. E., \& Polo, A. J. (2012). Academic achievement and depressive symptoms in low-income Latino youth. Journal of Child and Family Studies, 21(4), 565-577. 